\title{
Catálogo nacional de instituciones de investigación con actividades en nanociencias y nanotecnología - Parte 2
}

\author{
Rodolfo Zanella Specia, Gian C. Delgado Ramos y \\ Oscar E. Contreras López (coordinadores)
}

El Catálogo nacional de instituciones de investigación con actividades en nanociencias y nanotecnología es una iniciativa de nanoUNAM, consorcio académico de la UNAM integrado en 2009 por el Centro de Ciencias Aplicadas y Desarrollo Tecnológico (CCADET), el Centro de Nanociencias y Nanotecnología $(\mathrm{CNyN})$ y el Centro de Investigaciones Interdisciplinarias en Ciencias y Humanidades (CEIICH). Desde sus orígenes, nanoUNAM está interesado en impulsar el diálogo interdisciplinario de alta calidad sobre los avances, promesas e implicaciones de las nanociencias y la nanotecnología $(\mathrm{NyN})$ con el objeto de enriquecer la toma de decisiones nacionales referentes a la maximización y distribución de beneficios, la definición de responsabilidades y la minimización de costos innecesarios o no deseados; razón por la cual está integrado por entidades, tanto del subsistema de la Investigación Científica como del subsistema de Humanidades.

Como lo precisamos en su primera parte, este Catálogo es un aporte clave para dilucidar el estado del arte de la $\mathrm{NyN}$ en las instituciones de investigación con actividades en NyN, razón por la cual se pretende ofrecer una panorámica actual y robusta acerca de las actividades de investigación, docencia y extensión universitaria, relacionadas con las nanociencias y la nanotecnología que se realizan en las instituciones de investigación del país. Entre los aspectos clave que interesa destacar están las líneas de investigación en $\mathrm{NyN}$ desarrolladas y en curso, la infraestructura disponible, los instrumentos de protección de propiedad intelectual solicitados u otorgados, la docencia y formación de recursos humanos (incluyendo licenciatura y posgrados en $\mathrm{NyN}$, de ser el caso), y los principales logros alcanzados. Consideramos que dicha información no sólo permitirá tener un panorama más fino acerca del estado del arte de la $\mathrm{NyN}$ en el país, sino poder ser pieza clave para potenciar sinergias entre las instituciones que lo conforman y de éstas con otras instituciones extranjeras. $\mathrm{Al} \mathrm{mismo} \mathrm{tiempo,} \mathrm{se} \mathrm{pretende} \mathrm{al} \mathrm{Catálogo}$ como referente de información y diagnóstico para tomadores de decisiones, inversionistas públicos y privados, y público en general.

El Catálogo está dividido en tres partes. El presente número de Mundo Nano. Revista Interdisciplinaria en Nanociencias y Nanotecnología hace entrega del segundo grupo de entidades. Hasta el momento, se han catalogado 
FIGURA 1. Clasificación de instituciones de investigación con actividades de NyN empleada. En azul instituciones incluidas en esta segunda parte. En gris, instituciones consideradas en la clasificación que no figuran en esta segunda parte.

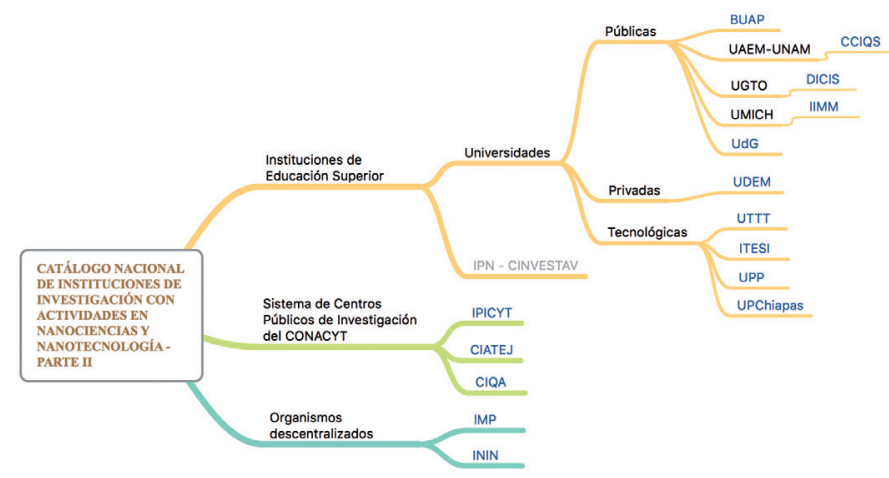

29 instituciones: ocho centros públicos de investigación del CONACyT, siete universidades públicas y algunas de sus múltiples entidades, dos universidades privadas, cuatro instituciones tecnológicas, y tres organismos descentralizados del gobierno federal.

Reconociendo que hay importantes instituciones ausentes, donde destaca el IPN-CINVESTAV, posterior a esta entrega se preparará un diagnóstico integral en el que se incluirán, de ser posible, las entidades ausentes que estén dispuestas a participar en este esfuerzo. El análisis integral se publicará en 2017.

La figura 1 muestra en orden estrictamente alfabético las instituciones presentadas en esta segunda parte, según la siguiente clasificación: instituciones de educación superior públicas y privadas, centros públicos de investigación del CONACyT y organismos descentralizados.

Agradecemos la disposición y trabajo de los responsables institucionales de cada uno de los trabajos aquí incluidos, así como el decidido apoyo institucional y financiero de la Coordinación de la Investigación Científica y de la Coordinación de Humanidades de la UNAM por su comprometido apoyo institucional y económico. Esperamos que este esfuerzo conjunto, tanto de entidades editoras y financiadoras, coordinadores del Catálogo y entidades participantes, contribuya efectivamente en el fortalecimiento de las NyN, la innovación, el desarrollo tecnológico y la regulación de materiales nanoestructurados y nanoproductos en el país. 